\title{
Single Copper Atoms Enhance Photoconductivity in
} $\mathrm{g}-\mathrm{C}_{3} \mathrm{~N}_{4}$

Matt D. Capobianco, ${ }^{\dagger}$ Brian Pattengale, ${ }^{\dagger},{ }^{*}$ Jens Neu, ${ }^{\dagger},{ }^{*}$ Charles A. Schmuttenmaer, ${ }^{\dagger}, \S$

'Department of Chemistry and Yale Energy Sciences Institute, Yale University, New Haven, Connecticut 06520-8107, United States

†Department of Molecular Biophysics and Biochemistry and Yale Microbial Sciences Institute, Yale University, New Haven, Connecticut 06520-8107

${ }^{\S}$ Deceased July 26, 2020

\section{AUTHOR INFORMATION}

\section{Corresponding Author}

*Brian Pattengale; brian.pattengale@yale.edu

*Jens Neu; jens.neu@yale.edu

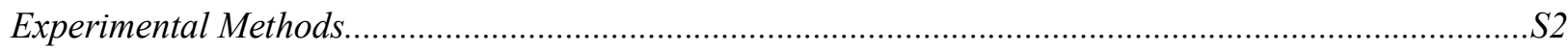

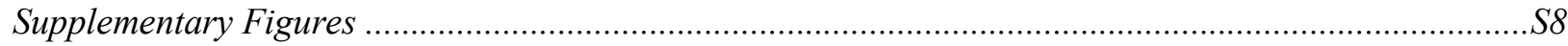

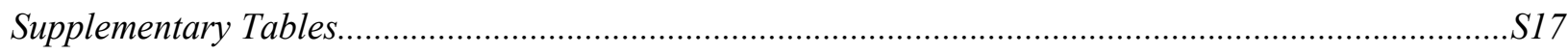

Atomic Cartesian Coordinates for EXAFS Models .............................................................................

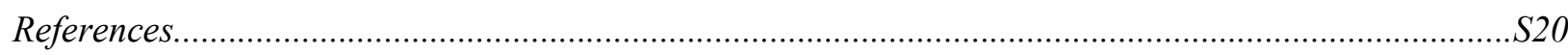




\section{Experimental Methods:}

Synthesis of $g-C_{3} N_{4}$ and $C u-g-C_{3} N_{4}$

Both $\mathrm{g}-\mathrm{C}_{3} \mathrm{~N}_{4}$ and $\mathrm{Cu}-\mathrm{g}-\mathrm{C}_{3} \mathrm{~N}_{4}$ were synthesized by a procedure adapted from Chung et al. ${ }^{1}$ All materials were commercially available and used without further purification. To produce $g-\mathrm{C}_{3} \mathrm{~N}_{4}$, about $2.5 \mathrm{~g}$ of dicyandiamide was added to an alumina crucible. For $\mathrm{Cu}-\mathrm{g}-\mathrm{C}_{3} \mathrm{~N}_{4}$, about $3 \mathrm{~g}$ of dicyandiamide and $2 \mathrm{mmol}$ of $\mathrm{CuCl}_{2} \cdot 2 \mathrm{H}_{2} \mathrm{O}$ were mixed in an alumina crucible. Crucibles were covered and the tops were wrapped in aluminum foil. The crucibles were places in a muffle furnace, at separate times, and heated to $550{ }^{\circ} \mathrm{C}$ for 4 hours at a ramp of $5^{\circ} \mathrm{C} / \mathrm{min}$ and then allowed to ambient cool. Lastly, the samples were removed from the crucibles and ground into a powder using a mortar and pestle.

\section{Fabrication of Films}

Film fabrication techniques were adapted from Ito et al. ${ }^{2}$ All materials were used without further purification. First, a solution of ethyl cellulose in $4.5 \mathrm{~g}$ of ethanol was prepared using $0.25 \mathrm{~g}$ of $10 \mathrm{cps}$ ethyl cellulose and $0.25 \mathrm{~g}$ of $22 \mathrm{cps}$ ethyl cellulose. The solution was vigorously stirred until the ethyl cellulose dissolved completely. Then, $1 \mathrm{~g}$ of $\mathrm{g}-\mathrm{C}_{3} \mathrm{~N}_{4}$ sample was added to $20 \mathrm{~mL}$ of ethanol with $167 \mu \mathrm{L}$ of glacial acetic acid and $833 \mu \mathrm{L}$ of DI water in a $50 \mathrm{~mL}$ centrifuge tube. The solution was horn sonicated for 10 minutes in an ice bath. After, $3.33 \mathrm{~g}$ of $\alpha$-terpineol was added to the solution, shaken vigorously, and horn sonicated for 15 minutes in an ice bath. The ethyl cellulose solution prepared earlier was added to the solution and then horn sonicated for an addition 15 minutes in an ice bath. The solution was placed into a rotovap to remove excess solvent and the resulting paste was collected. The paste was doctor bladed, using Scotch Magic tape as a spacer, onto a piece of cleaned quartz or Silicon. The quartz was cleaned by sonicating the substrate in DI water, acetone, 2-propanol, and ethanol for 10 minutes each. Lastly, the films were heated in a tube furnace by the following steps: $180{ }^{\circ} \mathrm{C} /$ hour to $370{ }^{\circ} \mathrm{C}$, hold at 370 ${ }^{\circ} \mathrm{C}$ for 5 minutes, $180{ }^{\circ} \mathrm{C} /$ hour to $470{ }^{\circ} \mathrm{C}, 10$ minutes at $470{ }^{\circ} \mathrm{C}$. Undoped $\mathrm{g}-\mathrm{C}_{3} \mathrm{~N}_{4}$ films were heated under air and $\mathrm{Cu}-\mathrm{g}-\mathrm{C}_{3} \mathrm{~N}_{4}$ films were heated under $\mathrm{N}_{2}$ to prevent oxidation of $\mathrm{Cu}$. The resulting films are approximatly $12 \mu \mathrm{m}$ thick. 


\section{Materials Characterization}

XRD measurements were taken Rigaku SmartLab X-ray diffractometer. UV-Visible spectra were collected using a Shimadzu UV-2600 with the integrating sphere attachment. The Kubelka-Munk function F(R) was used to display the diffuse reflectance UV-visible data, where $\mathrm{R}$ is the reflectance: ${ }^{3}$

$F(R)=\frac{(1-R)^{2}}{2 R}$

(Equation S1)

Emission and excitation spectra were collected using a Horiba Fluoromax Plus spectrometer. XPS data was collected using a PHI VersaProbe II Scanning XPS Microprobe where the powder samples were just pressed onto a piece of double-sided tape and the film samples were attached using double-sided tape. Elemental Analysis was performed by Robertson-Microlit laboratories. CHN analysis was performed to determine the amount of $\mathrm{C}, \mathrm{H}$, and $\mathrm{N}$, and ICP-OES was performed for $\mathrm{Cu}$. Film thicknesses were measured using a Dektak mechanical profilometer.

\section{EXAFS Measurements}

EXAFS measurements were performed at beamline 6-BM (BMM) at Brookhaven National Laboratory. Samples were sandwiched in Kapton tape and measured in transmission mode using ion chamber detectors. A $\mathrm{Cu}$ foil reference was collected simultaneously using an additional ion chamber beyond the chambers detecting transmission through the sample and was used for calibration. A Si(111) monochromator provided monochromatic X-rays that were not focused further and data was collected in a point acquisition mode. Analysis was performed using the Demeter suite of programs. ${ }^{4}$ The normalized $\mathrm{Cu}-\mathrm{g}-\mathrm{C}_{3} \mathrm{~N}_{4}$ data was $\mathrm{k}^{3}$-weighted and the K-space data was Fourier transformed in the K-range of 2.77 12.45 using a Hanning window. Preliminary EXAFS analysis was performed for the first shell using a quick first shell fit in Artemis without a model. The full analysis utilized the models shown in Figure 1c in the main text corresponding to the cartesian coordinates provided in the SI. Fitting was performed iteratively to determine best fits varying $\sigma^{2}, \Delta \mathrm{E}_{0}$, and $\Delta \mathrm{R}$. The final reported fits with uncertainty were 
performed fixing $\mathrm{N}$ and $\Delta \mathrm{E}_{0}$, and, where appropriate, $\sigma^{2}$ if fitting resulted in a physically unreasonable value. The fit uncertainties are shown in the data in Table 1, main text.

\section{Time-resolved Terahertz Measurements}

The spectrometer utilized for OPTP and TRTS experiments was a Spitfire Ace amplifier which uses a Ti:Sapphire crystal to produce $800 \mathrm{~nm}$ pulses with a $35 \mathrm{fs}$ FWHM at a $1 \mathrm{kHz}$ rep rate. The beam is split into three separate beams: terahertz generation, an optical pump, and a detection beam. The optical pump goes through a $\beta$-barium borate (BBO) crystal to frequency double to excite the samples at $400 \mathrm{~nm}$ (fwhm

diameter $\mathrm{d} \approx 6.2 \mathrm{~mm}$; fluence of $0.575 \mathrm{~mJ} \mathrm{~cm}^{-2}$ ). The generation line produces terahertz by inducing an air plasma by focusing $800 \mathrm{~nm}$ and frequency doubled (using BBO) $400 \mathrm{~nm}$ light and is measured via electro-optic sampling in ZnTe (110). OPTP measurements were performed by directly measuring the change in the peak of terahertz, $\Delta \mathrm{THz}$, as function of pump time. The pump line was chopped and a lockin amplifier was fixed at that frequency. A more detailed description of the instrument is shown in Figure S8 and in a previous work. ${ }^{5}$ Frequency-dependent time-resolved (TRTS) measurements were performed at a pump delay of $1.4 \mathrm{ps}$ for $\mathrm{Cu}-\mathrm{g}-\mathrm{C}_{3} \mathrm{~N}_{4}$ by collecting the time-domain difference signal for the photoexcited sample, followed by a reference non-photoexcited time-domain trace. The analysis details are shown in a separate section below. The Drude-Smith model was used to fit the complex photoconductivity, where $\mathrm{N}$ is the photoexcited carrier density, e is the elementary charge, $\tau_{\mathrm{DS}}$ is the scattering time, $\mathrm{m}$ is the carrier mass, and $\mathrm{c}$ is the persistence of velocity parameter. ${ }^{6,7}$

$\tilde{\sigma}(\omega)=\frac{N e^{2} \tau_{D S} / m}{1-i \omega \tau_{D S}}\left[1+\frac{c}{1-i \omega \tau_{D S}}\right]$ (Equation S2)

Steady-State Terahertz Measurements

Terahertz time domain spectroscopy (THz-TDS) measurements were performed using a system described in previous work. ${ }^{8}$ In brief, an $800 \mathrm{~nm}$ fs-pulsed laser, outputted from a Spectra Physics Mai 
Tai, was utilized and split into a generation and detection line. Terahertz radiation was generated and detected using photoconductive antennas. The terahertz pulse is measured by varying the time delay within the detection line. Samples were placed into a cryostat to control the temperature, in this case 300 K, $200 \mathrm{~K}$, and $100 \mathrm{~K}$, and the position was set using a position stage. Samples were deposited on $\mathrm{Si}$ substrates (details) using 6 doctor bladed layers.

\section{OPTP Sample Preparation}

OPTP measurements on powder samples were taken using a tape cell. A detailed description of the tape cell method is described in previous work. ${ }^{9}$ Briefly, a $7 \mathrm{~mm}$ diameter hole was punched into a business card section. Then a piece of acrylic tape was placed onto the bench, the cell was placed on the tape, and the hole was filled evenly with powder. Another piece of acrylic tape was placed on top and gently pressed by hand to sandwich the sample. Sample thicknesses of roughly $300 \mu \mathrm{m}$ are obtained. Film samples were measured directly as-prepared in the Fabrication of Films section.

\section{Photoelectrochemical Cell (PEC) Experiments}

PEC experiments were performed in a three-electrode cell with the sample doctor-bladed on an FTO-glass working electrode, platinum counter electrode, and $\mathrm{Ag} / \mathrm{AgCl}$ reference electrode in $0.2 \mathrm{M} \mathrm{Na}_{2} \mathrm{SO}_{4}$. A 300W Xenon lamp was used for chopped irradiation with and without a $400 \mathrm{~nm}$ long pass filter in place. The cell was purged with $\mathrm{N}_{2}$ and irradiation was performed through a flat quartz window on the cell. A $1 \mathrm{~V}$ bias voltage was applied during the chronoamperometry experiments and the film was held at a $1 \mathrm{~V}$ potential for $10 \mathrm{~s}$ prior to collecting data to reduce background currents. Data was baseline shifted for comparisons. 


\section{THz-TDS and TRTS Data Analysis}

The full details of the data processing are published elsewhere. ${ }^{8,10}$ Briefly, to determine frequency resolved THz photoconductivity and static ground state refractive index, TRTS and TDS are used respectively. Two measurements per data processing are performed, a reference and a sample measurement. In the case of TRTS this reference measurement is the THz transmission through the sample, without photoexcitation. For the TDS the reference is a blank substrate, without film. The second measurement for TRTS probes the photoexcited material, 1.4 ps after excitation. For TDS the sample material is measured, in its ground state at $300 \mathrm{~K}, 200 \mathrm{~K}$ and $100 \mathrm{~K}$ respectively.

Based on these two measurements the refractive indices and photoconductivity are calculated. This is done without any approximations, by numerically solving the transfer equations. Based on the known geometry the transfer function can be set up. An electromagnetic wave travels through a medium $j$ with a thickness $d_{j}$ the complex refractive index $n_{j}$ experience exponential dampening as well as phase delay described by

$P_{j}=e^{-n_{j} k \mathrm{id}_{\mathrm{j}}}$

With $\mathrm{i}$ as imaginary unit and $k$ the wavevector in vacuum. On an interface between $m$ and $j$ parts of the incident wave are reflected or transmitted according to

$\rho_{\mathrm{mj}}=\frac{n_{m}-n_{j}}{n_{m}+n_{j}} ; \tau_{\mathrm{mj}}=\frac{2 n_{m}}{n_{m}+n_{j}}$

The transfer functions for the two TDS and two TRS measurements for the time window used in this experiment are:

TDS Reference: $E^{T D S}{ }_{r e f}=\tau_{a s} P_{s} \tau_{s a}$; with $a$ referring to air and $s$ to the substrate

(Equation S5)

TDS Sample: $E_{s a m p}^{T D S}=\tau_{a s} P_{s} \tau_{s x} P_{x} \tau_{x a} \frac{1}{1+\rho_{s x} \rho_{x s} P_{x} P_{x}}$; with $x$ referring to the sample and the last term describing internal reflections within the sample material

(Equation S6) 
TRTS Reference $E_{r e f}^{T R T S}=\tau_{a s} P_{s} \tau_{s x} P_{x} \tau_{x a} \frac{1}{1+\rho_{s x} \rho_{x s} P_{x} P_{x}}$

(Equation S7)

TRTS Sample $E_{s a m p}^{\text {TRTS }}=\tau_{a s} P_{s} \tau_{s x *} P_{x *} \tau_{x * a} \frac{1}{1+\rho_{s x * \rho_{x * s} P_{x *} P_{x *}}}$

(Equation S8)

with $\mathrm{x}^{*}$ referring to the photoexcited sample.

Based on these consideration we can define the transfer equations as

$\frac{E_{s a m p}^{T D S, E x p}}{E_{r e f}^{T D S, E x p}}=\frac{\tau_{s x}}{\tau_{s a}} P_{x} \tau_{x a} \frac{1}{1+\rho_{s x} \rho_{x S} P_{x} P_{x}}$

(Equation S9)

And for TRTS as

$\frac{E_{s a m p}^{T R T S, E x p}}{E_{r e f}^{T R T S, E x p}}=\frac{\tau_{s x *}}{\tau_{s x}} \frac{P_{x *}}{P_{x}} \frac{\tau_{x * a}}{\tau_{x a}} \frac{1+\rho_{s x} \rho_{x s} P_{x} P_{x}}{1+\rho_{s x *} \rho_{x * s} P_{x *} P_{x *}}$

(Equation S10)

These equations relate the experimental measured $\mathrm{THz}$ E-field with the complex refractive index. The real and the imaginary part of the refractive index both contribute to the phase and amplitude ratio of the experimental and theoretical transfer function. The above-mentioned equations are solved numerically for the complex refractive index (with known sample thickness). The photoconductivity is then determined via

$n *=\sqrt{\epsilon *}=\left(\epsilon-i \frac{\sigma}{\omega \epsilon_{0}}\right)^{1 / 2}$

with the assumption that the photoexcitation is solely changing the conductivity and not the static permittivity. 


\section{Supplementary Figures}

a)

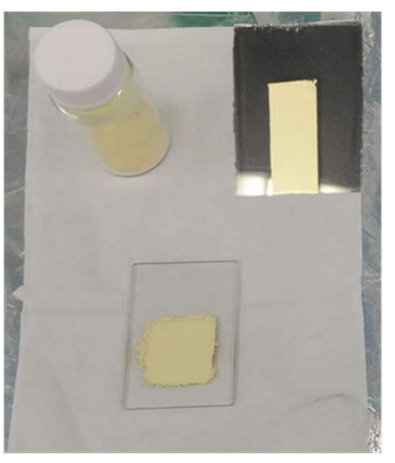

b)

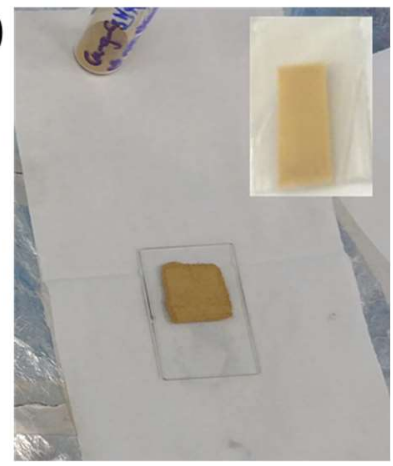

Figure S1. (a) Photograph of undoped $g-\mathrm{C}_{3} \mathrm{~N}_{4}$ powder packed onto $\mathrm{pXRD}$ plate (a) and film (inset). (b) photograph of $\mathrm{Cu}-\mathrm{g}-\mathrm{C}_{3} \mathrm{~N}_{4}$ and film (inset).
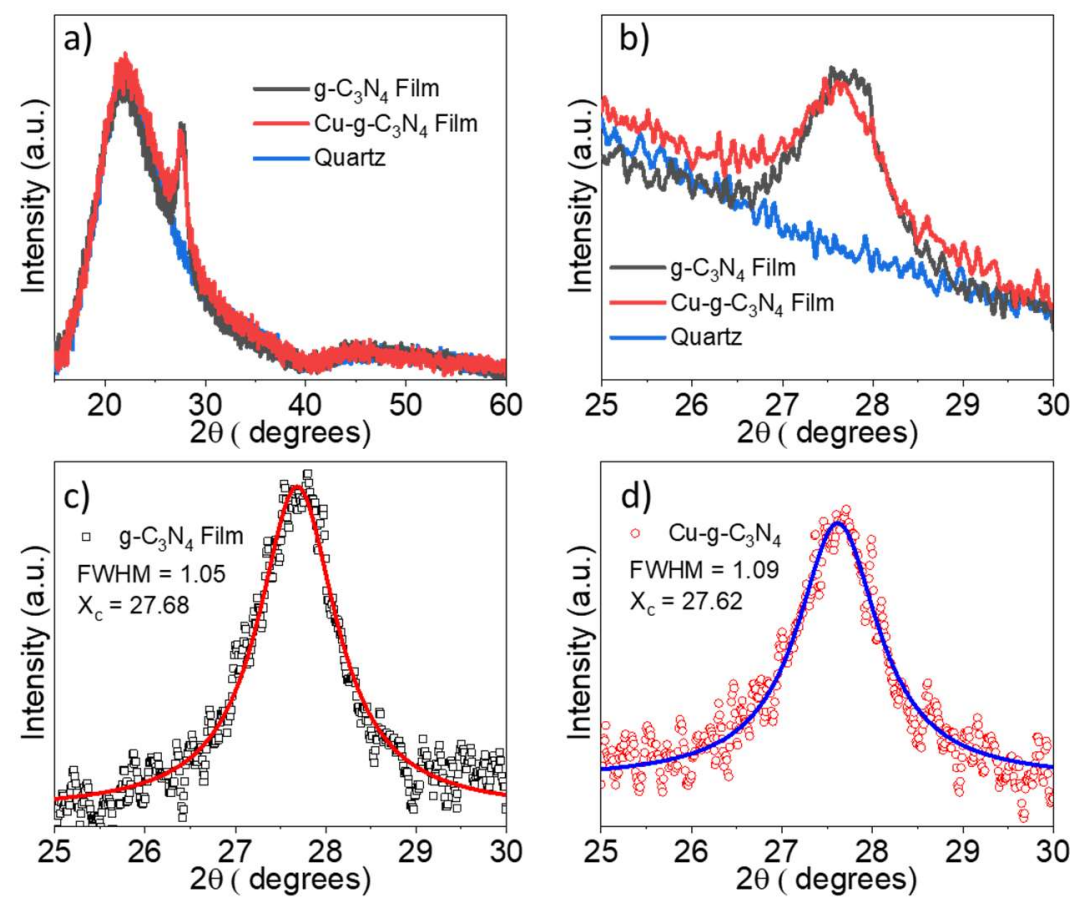

Figure S2. XRD results for $\mathrm{g}-\mathrm{C}_{3} \mathrm{~N}_{4}$ and $\mathrm{Cu}-\mathrm{g}-\mathrm{C}_{3} \mathrm{~N}_{4}$ (a) and enlarged region around the main diffraction feature (b) and Lorentzian fits (c-d) with the corresponding results in Table S1. Data for fitting was prepared by subtracting the quartz background from the data sets, and a vertical offset parameter was used in the fit to account for the baseline. 

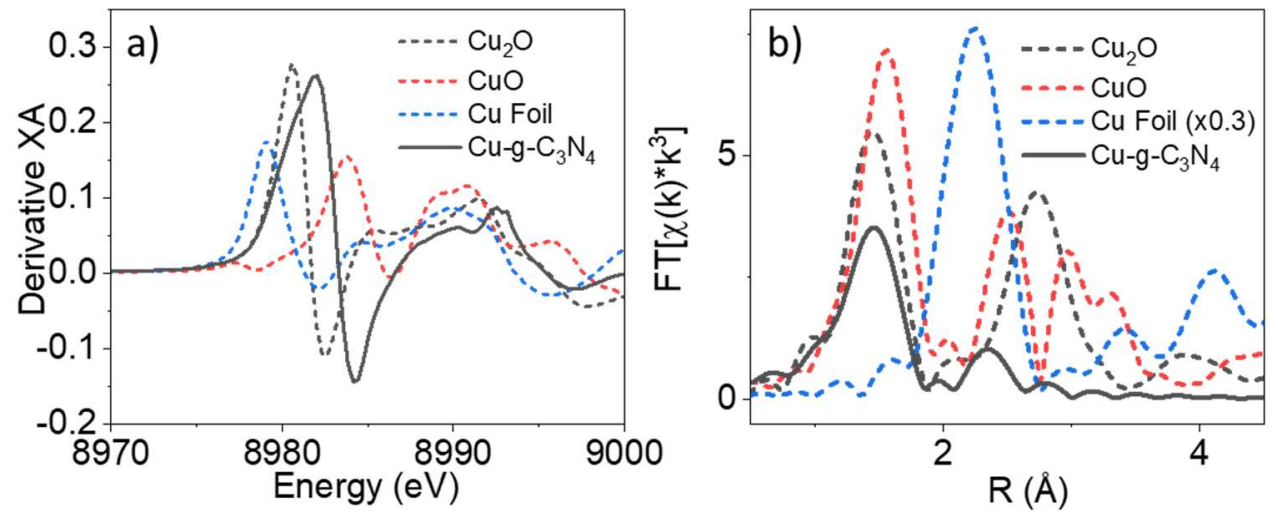

Figure S3. (a) First derivative XANES spectra and (b) R-space comparison of Cu-g- $\mathrm{C}_{3} \mathrm{~N}_{4}$ spectrum to reference spectra.
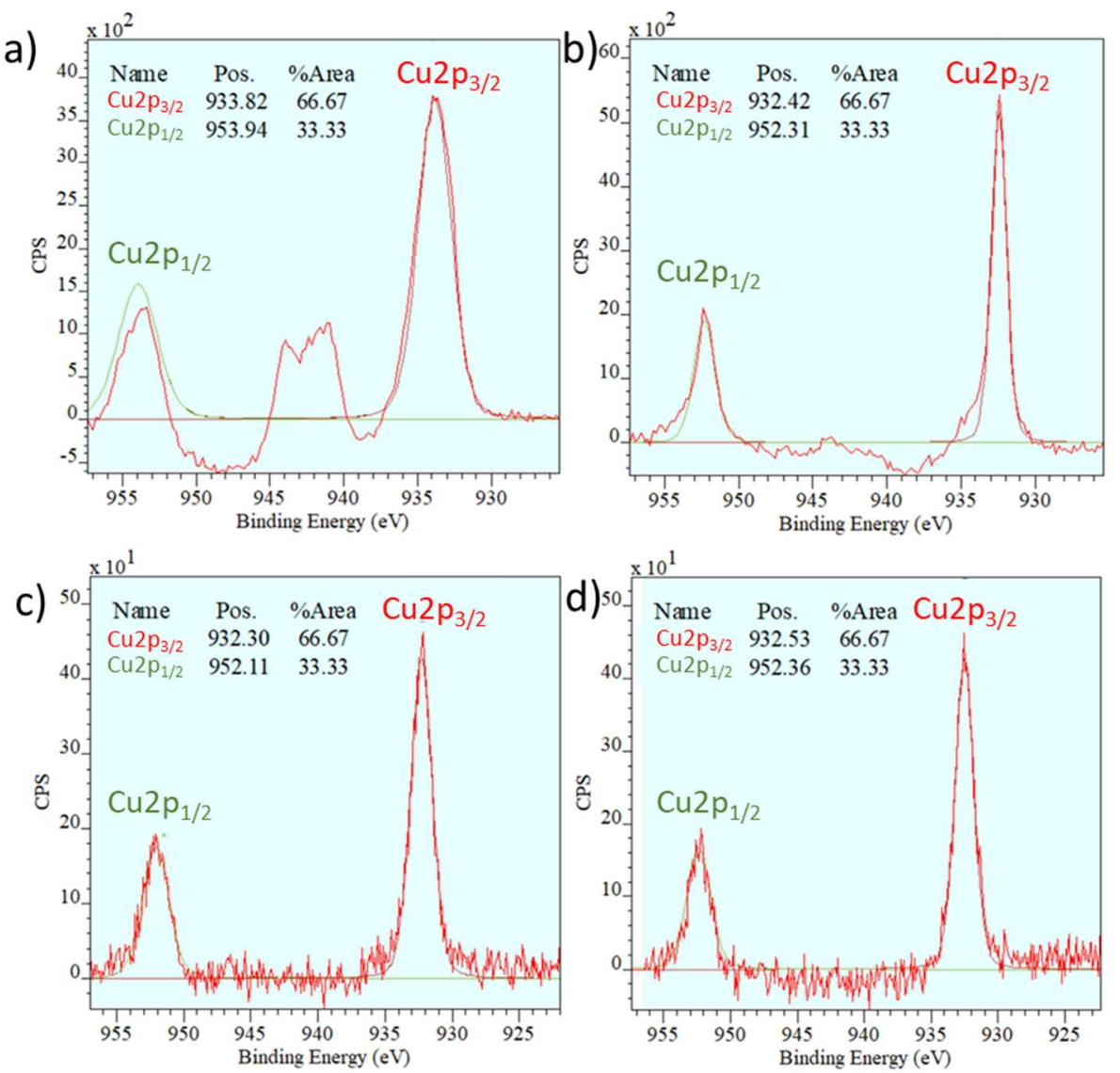

Figure S4. XPS spectra for $\mathrm{CuO}(\mathrm{a}), \mathrm{Cu}_{2} \mathrm{O}$ (b), $\mathrm{Cu}-\mathrm{g}-\mathrm{C}_{3} \mathrm{~N}_{4}$ powder (c) and $\mathrm{Cu}-\mathrm{g}-\mathrm{C}_{3} \mathrm{~N}_{4}$ film (d). The $\mathrm{CuO}$ spectrum in (a) contains a large characteristic satellite feature that affects the baseline but does not significantly affect the peak positions in energy. The fit peak positions for $\mathrm{Cu}_{2} \mathrm{O}$, the $\mathrm{Cu}^{+}$reference sample, are in agreement with those observed in the $\mathrm{Cu}-\mathrm{g}-\mathrm{C}_{3} \mathrm{~N}_{4}$ samples, confirming the oxidation state as $\mathrm{Cu}^{+}$. 

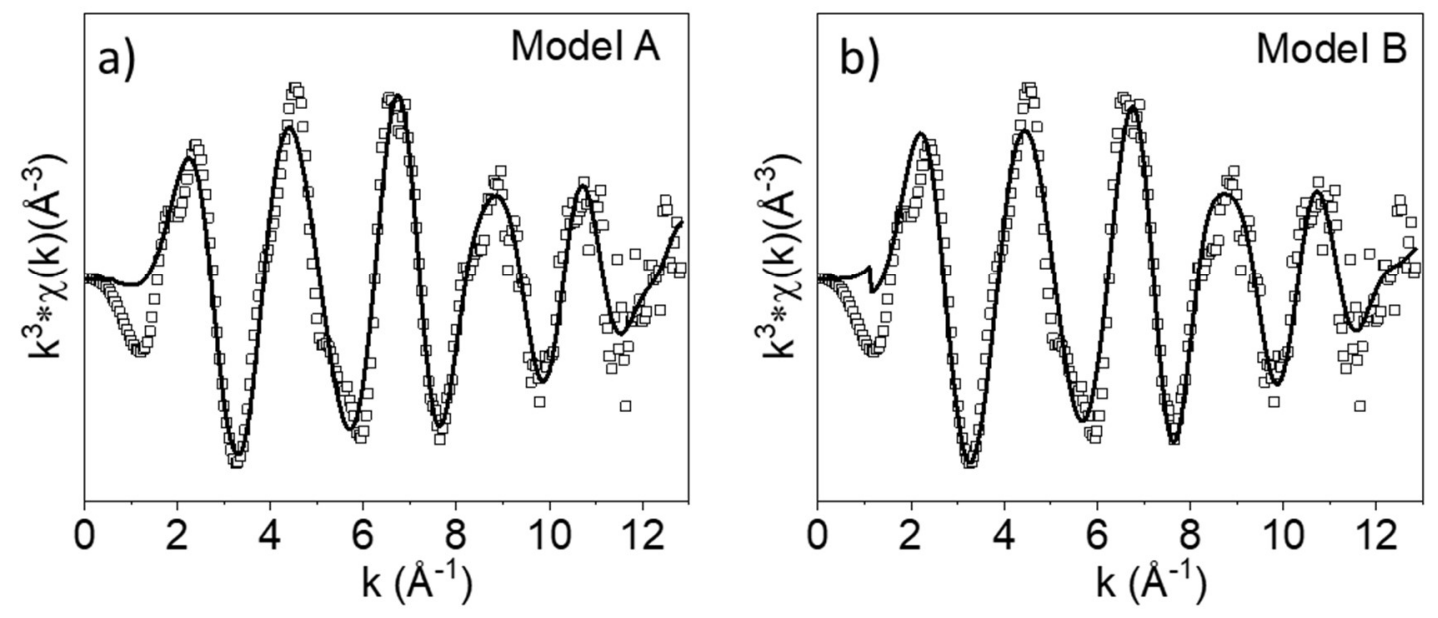

Figure S5. K-space EXAFS spectra and FEFF best fit lines for each fit model shown in Figure 1c, main text.
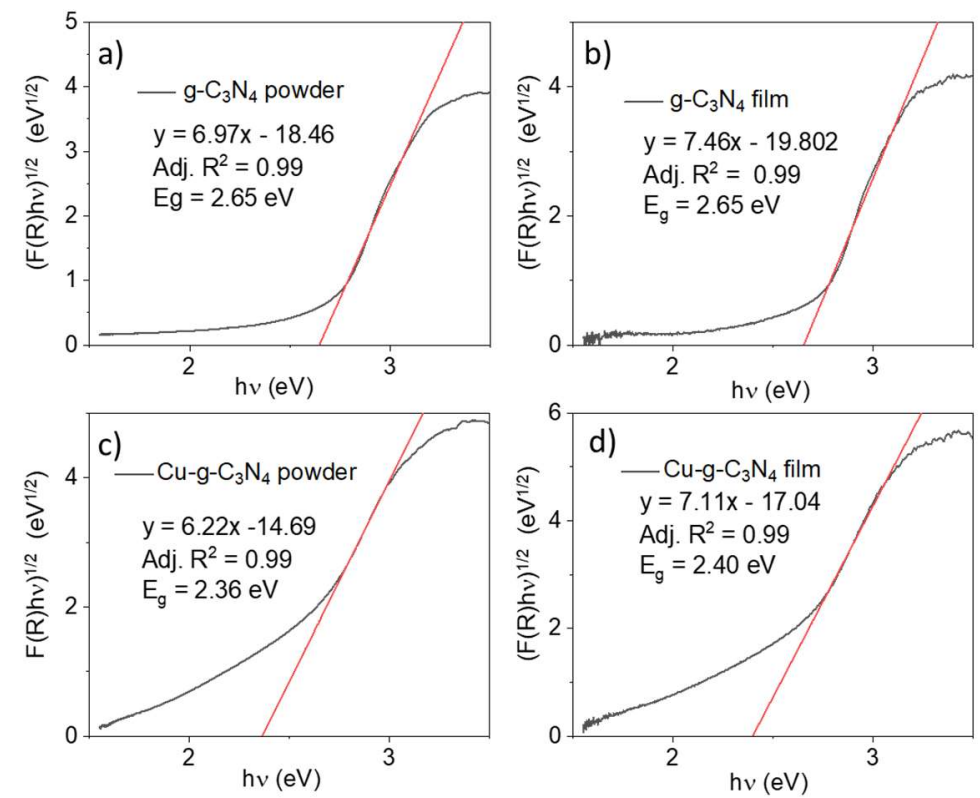

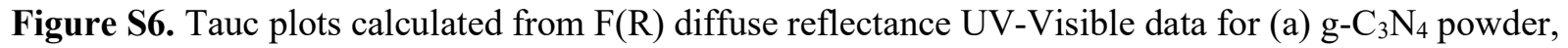
(b) $\mathrm{g}-\mathrm{C}_{3} \mathrm{~N}_{4}$ film, (c) Cu-g- $\mathrm{C}_{3} \mathrm{~N}_{4}$ powder, and (d) Cu-g- $\mathrm{C}_{3} \mathrm{~N}_{4}$ film. An exponent of $1 / 2$ (indirect transition) gives a bandgap in agreement with literature while an exponent of 2 (direct transition) gives a bandgap approximately $0.3 \mathrm{eV}$ too large. 


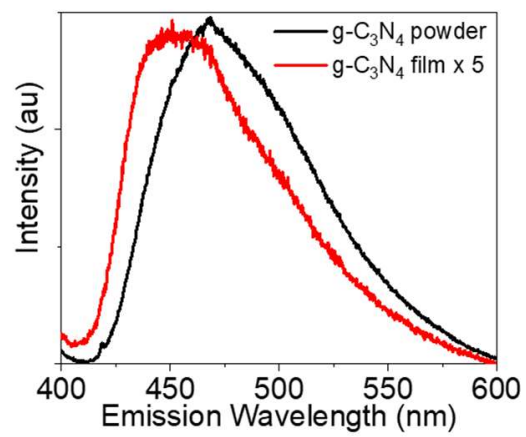

Figure S7. Comparison of $\mathrm{g}-\mathrm{C}_{3} \mathrm{~N}_{4}$ powder (black) and film (red) emission spectra under $380 \mathrm{~nm}$ excitation. The data is identical to the data shown in main text, Figure $2 \mathrm{c}$, d, however $\mathrm{g}-\mathrm{C}_{3} \mathrm{~N}_{4}$ film data has been multiplied for comparison, as denoted in the legend.

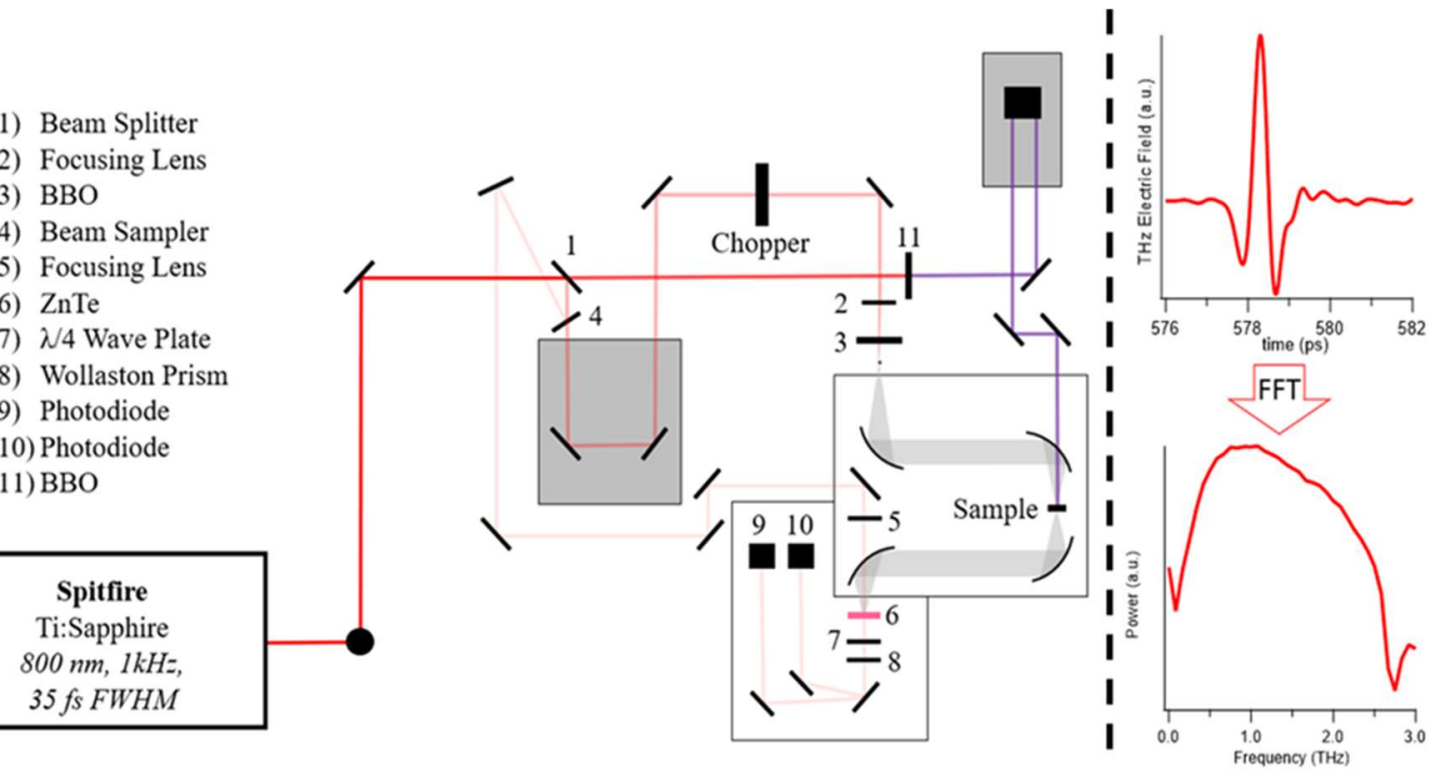

Figure S8. Schematic representation (not to scale) of time-resolved $\mathrm{THz}$ spectrometer used in OPTP experiments as further described in the experimental (left panel). The chopper is shown in the $\mathrm{THz}$ generation line in the figure, but is moved to the pump line for collection of the difference signal in OPTP experiments with the generation delay line fixed at the peak of the $\mathrm{THz}$ time domain pulse. The grey boxes shown in the pump and generation delay lines are mechanical delay stages.

Representative THz time domain pulse transmitted through $\mathrm{g}-\mathrm{C}_{3} \mathrm{~N}_{4}$ and fast Fourier-transformed (FFT) power spectrum showing the approximate bandwidth of the pulse (right panel). 

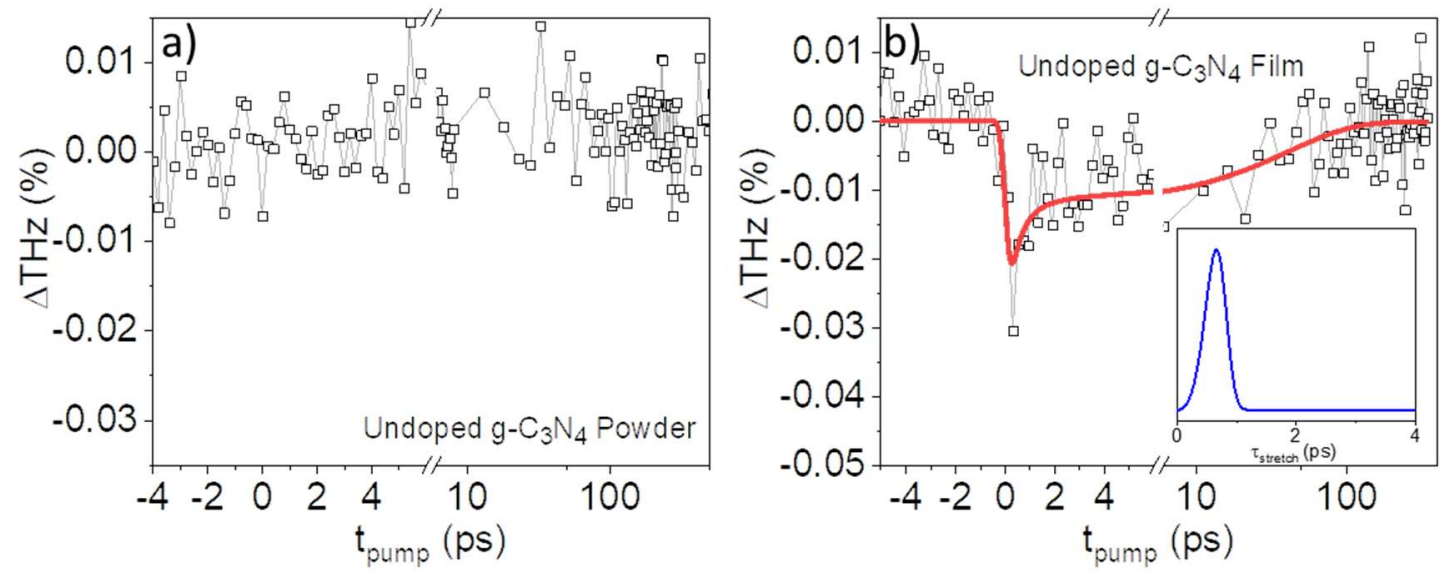

Figure S9. OPTP for undoped film and powder. See Table S2 for fit results of figure (b). Inset of (b) shows the corresponding calculated distribution of the stretched time constant. 

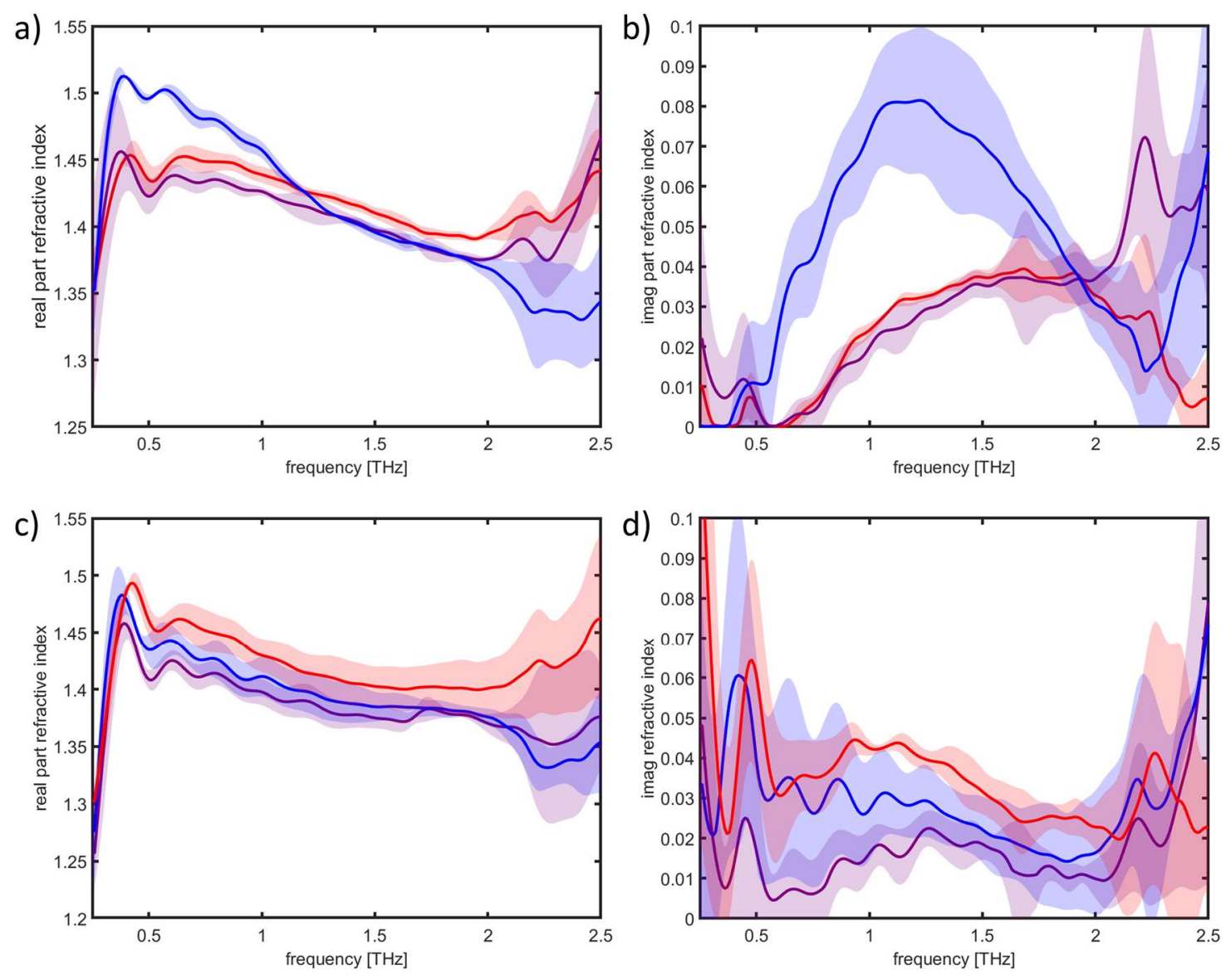

Figure S10. Temperature-dependent THz-TDS results for $\mathrm{g}-\mathrm{C}_{3} \mathrm{~N}_{4}(\mathrm{a}-\mathrm{b})$, and $\mathrm{Cu}-\mathrm{g}-\mathrm{C}_{3} \mathrm{~N}_{4}$ (c-d) with shading for the error bars. The red $(300 \mathrm{~K})$, violet $(200 \mathrm{~K})$, and blue $(100 \mathrm{~K})$ traces do not show a significant trend or difference as a function of temperature. 

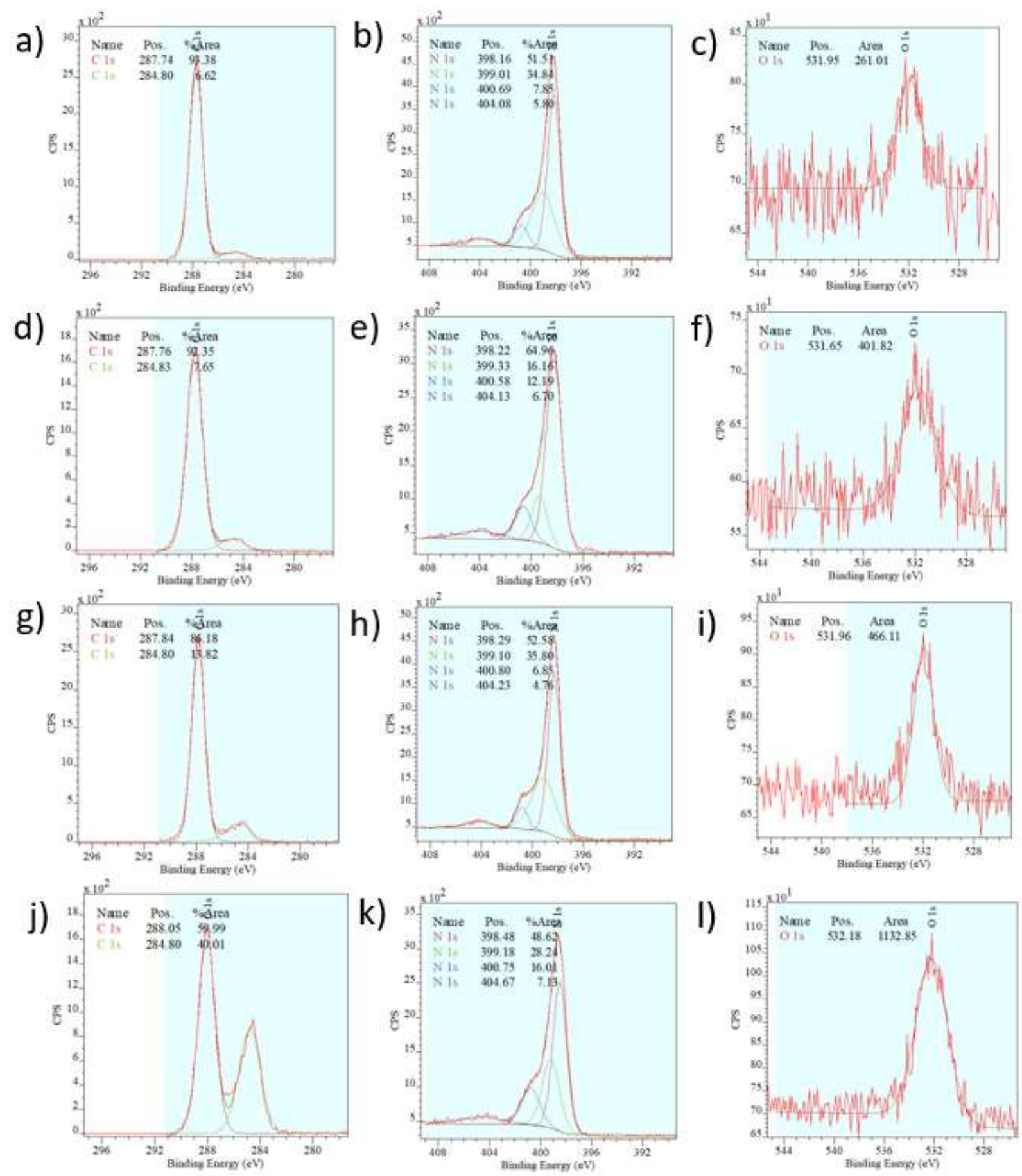

Figure S11. XPS results comparing g- $\mathrm{C}_{3} \mathrm{~N}_{4}$ Powder (a-c), Cu-g- $\mathrm{C}_{3} \mathrm{~N}_{4}$ powder (c-e), g- $\mathrm{C}_{3} \mathrm{~N}_{4}$ film (g-i), and $\mathrm{Cu}-\mathrm{g}-\mathrm{C}_{3} \mathrm{~N}_{4}$ film (j-1). See Figure $\mathrm{S} 11$ for $\mathrm{N}$ peak assignments. 


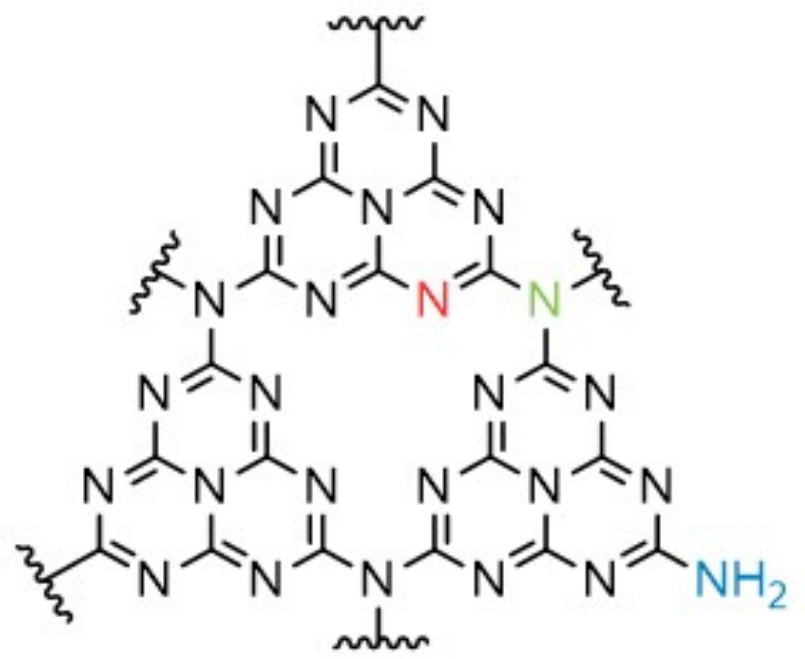

Figure S12. Depiction of the different components from N 1s peak corresponding to the color of the component in Figure S10 (The violet component corresponds to charge effects) based on literature assignment. ${ }^{11,12}$

The small increase in binding energy in the $\mathrm{N} 1 \mathrm{~s}$ spectra from the $\mathrm{g}-\mathrm{C}_{3} \mathrm{~N}_{4}$ powder to $\mathrm{Cu}-\mathrm{g}-\mathrm{C}_{3} \mathrm{~N}_{4}$ powder implies that $\mathrm{Cu}$ is binding to the $\mathrm{N}$ atoms. This trend is not seen in the $\mathrm{C} 1 \mathrm{~s}$ spectra suggesting that $\mathrm{Cu}$ does not bind with the $\mathrm{C}$ atoms, as expected. The change in relative area seen in the $\mathrm{C} 1 \mathrm{~s}$ components from the powder spectra to the film spectra, especially evident in the $\mathrm{Cu}$ doped species, suggests the film fabrication process alters the material in some way. ${ }^{13}$ The $\mathrm{C} 1 \mathrm{~s}$ spectrum has a component around $287.7 \mathrm{eV}$ corresponding to the $\mathrm{C}$ atoms in the heptazine structure and a component at $284.8 \mathrm{eV}$ corresponding to $\mathrm{C}-\mathrm{C}$ interactions, which is always observed in XPS due to surface contaminants, but in this system can also be attributed C-C defects. ${ }^{14}$ Therefore, a relative intensity increase in the $284.8 \mathrm{eV}$ component in the film samples implies the presence of more of these sites. 

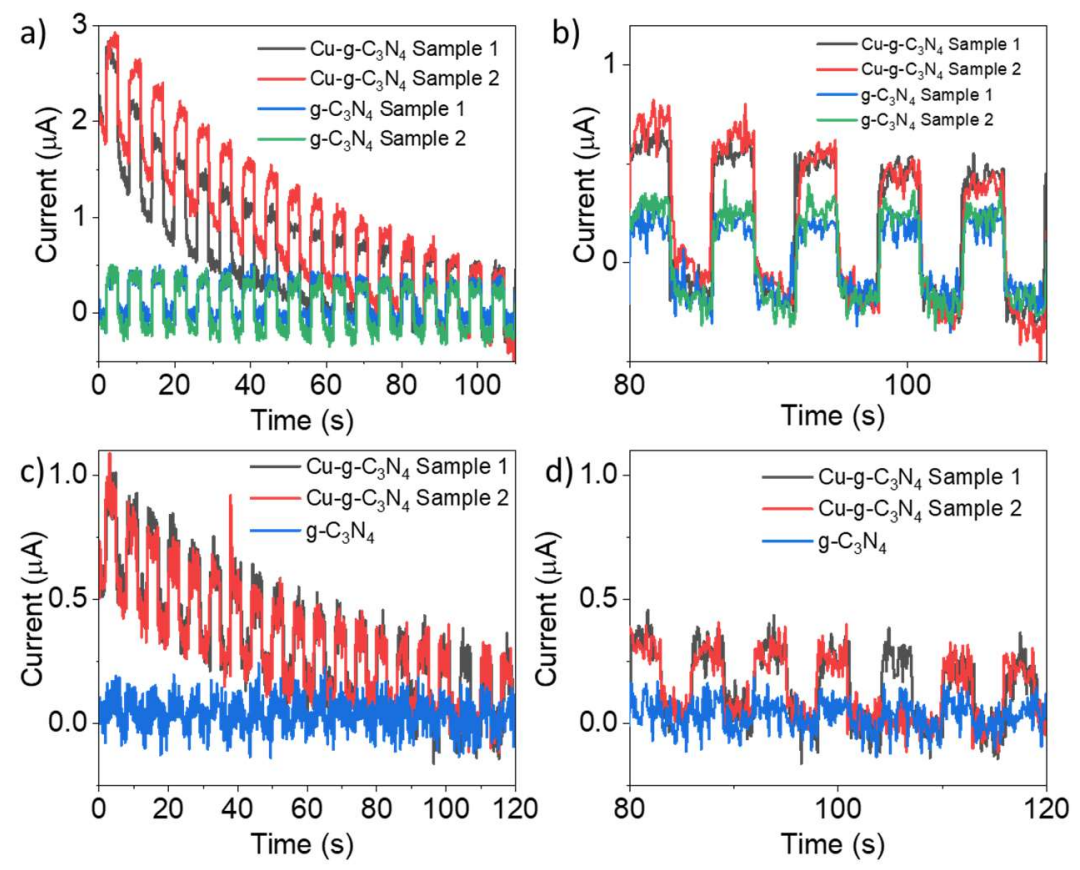

Figure S13. Three-electrode photoelectrochemical cell (PEC) experiments on film $\mathrm{g}_{-} \mathrm{C}_{3} \mathrm{~N}_{4}$ and film Cu-g$\mathrm{C}_{3} \mathrm{~N}_{4}$ samples. The experiment is performed with the sample deposited on FTO as the working electrode, a platinum counter electrode, and an $\mathrm{Ag} / \mathrm{AgCl}$ Reference electrode in $0.2 \mathrm{M} \mathrm{Na}_{2} \mathrm{SO}_{4}$. In panels (a) and (b) the chopped $300 \mathrm{~W}$ Xenon lamp output is not filtered, yielding both UV and visible irradiation while panels (c) and (d) are performed with a 400nm low pass filter in place, yielding only visible irradiation. The experiments were performed at an applied bias of $1 \mathrm{~V}$ vs. $\mathrm{Ag} / \mathrm{AgCl}$. In Cu-g- $\mathrm{C}_{3} \mathrm{~N}_{4}$, a dark current is observed due to the presence of $\mathrm{Cu}$, implying that charges are removed from $\mathrm{Cu}^{+}$under applied bias whereas $g-\mathrm{C}_{3} \mathrm{~N}_{4}$ lacks the prolonged dark current.

The comparison in (b) shows that $\mathrm{Cu}-\mathrm{g}-\mathrm{C}_{3} \mathrm{~N}_{4}$ has significantly enhanced photocurrent compared to the $g-\mathrm{C}_{3} \mathrm{~N}_{4}$ analogue under $\mathrm{UV}+$ visible irradiation. In (d), there is negligible photocurrent for $\mathrm{g}-\mathrm{C}_{3} \mathrm{~N}_{4}$ while the $\mathrm{Cu}$-modified analogue displays photocurrent. This result is consistent with the UV-Visible results that show a smaller bandgap and enhanced visible light absorption for $\mathrm{Cu}-\mathrm{g}-\mathrm{C}_{3} \mathrm{~N}_{4}$. As a whole, the PEC experiments corroborate the experimental results that $\mathrm{Cu}-\mathrm{g}-\mathrm{C}_{3} \mathrm{~N}_{4}$ has superior photoconductivity compared to $\mathrm{g}-\mathrm{C}_{3} \mathrm{~N}_{4}$. 


\section{Supplementary Tables}

Table S1. pXRD Lorentzian Fit Results. The following equation was used to fit pXRD peaks, where $y_{0}$ is the y-axis offset, $\mathrm{A}$ is the area, $w$ is the FWHM in degrees $2 \theta$, and $x_{c}$ is the peak center in degrees $2 \theta$. The interplane distance, $d$, is determined using $x_{c}$ in the Bragg equation.

$$
y=y_{0}+\frac{2 A}{\pi} \frac{w}{4\left(x-x_{c}\right)^{2}+w^{2}}
$$

\begin{tabular}{|c|c|c|c|c|c|}
\hline Sample & $y 0$ & $\mathrm{~A}$ & $\begin{array}{c}w \\
\text { (FWHM) }\end{array}$ & $x_{c}$ & $d(\AA)$ \\
\hline $\mathrm{g}-\mathrm{C}_{3} \mathrm{~N}_{4}$ & -16.28 & 69741.2 & 1.38 & 27.35 & 3.352 \\
\hline $\mathrm{Cu}-\mathrm{g}-\mathrm{C}_{3} \mathrm{~N}_{4}$ & 65.07 & 49998.7 & 1.11 & 27.59 & 3.333 \\
\hline${\mathrm{g}-\mathrm{C}_{3} \mathrm{~N}_{4} \text { film }}$ & -70.66 & 1022.26 & 1.05 & 27.68 & 3.315 \\
\hline $\mathrm{Cu}-\mathrm{g}-\mathrm{C}_{3} \mathrm{~N}_{4}$ film & 32.23 & 785.73 & 1.09 & 27.62 & 3.322 \\
\hline
\end{tabular}

Table S2. $\mathrm{Cu} \mathrm{K}$ edge XANES edge position determined by $1^{\text {st }}$ derivative peak and $1 / 3$ edge jump.

\begin{tabular}{lllll}
\hline Method & $\begin{array}{l}\mathbf{C u} \text { Foil } \\
\left(\mathbf{C u}^{\mathbf{0}}\right)\end{array}$ & $\mathbf{C u} \mathbf{O}\left(\mathbf{C u}^{+}\right)$ & $\mathbf{C u O}\left(\mathbf{C u}^{2+}\right)$ & $\mathbf{C u}-\mathbf{g}-\mathbf{C}_{3} \mathbf{N}_{4}$ \\
\hline $1^{\text {st }}$ Derivative & $8979.02 \mathrm{eV}$ & $8980.63 \mathrm{eV}$ & $8983.77 \mathrm{eV}$ & $8981.92 \mathrm{eV}$ \\
& & & & \\
$1 / 3$ Edge Jump & $8979.45 \mathrm{eV}$ & $8980.27 \mathrm{eV}$ & $8983.71 \mathrm{eV}$ & $8980.54 \mathrm{eV}$ \\
\hline
\end{tabular}

Table S3. OPTP fit results for the $\mathrm{g}_{-} \mathrm{C}_{3} \mathrm{~N}_{4}$ data shown in Figure $\mathrm{S} 3$.

\begin{tabular}{lllllll}
\hline Sample & fwhm (ps) & $\mathbf{A}_{\text {stretch }}$ & $\boldsymbol{\tau}_{\text {stretch }}(\mathbf{p s )}$ & $\boldsymbol{\beta}$ & $\mathbf{A}_{\mathbf{2}}$ & $\boldsymbol{\tau}_{\mathbf{2}}(\mathbf{p s})$ \\
\hline${\mathrm{g}-\mathrm{C}_{3} \mathrm{~N}_{4} \text { film }}$ & 0.4 & -0.022 & 0.4 & 0.82 & -0.011 & 41.6 \\
\hline
\end{tabular}

Table S4. Drude-Smith parameters for Cu-g- $\mathrm{C}_{3} \mathrm{~N}_{4}$ fit. The electron rest mass was fixed as the mass of a free electron in vacuum, giving an effective mass $\left(\mathrm{m}^{*}\right)$ of 1 . The c parameter fit to the limit value of -1 . See Equation S2.

\begin{tabular}{ccccc}
\hline Sample & $\mathbf{N}\left(\mathbf{m}^{-3}\right)$ & $\boldsymbol{\tau}_{\mathbf{D S}}(\mathbf{f s})$ & $\mathbf{m}^{*}$ & $\mathbf{c}$ \\
\hline $\mathrm{Cu}-\mathrm{g}-\mathrm{C}_{3} \mathrm{~N}_{4}$ film & $7.08 \times 10^{15}$ & 8.2 & 1 & -1 \\
\hline
\end{tabular}


Table S5. Percent Mass Determined by Elemental Analysis. The $\mathrm{C}$ to $\mathrm{N}$ is an atomic ratio.

\begin{tabular}{|c|c|c|c|c|c|}
\cline { 2 - 6 } \multicolumn{1}{c|}{} & $\mathbf{C}$ & $\mathbf{H}$ & $\mathbf{N}$ & $\mathbf{C u}$ & $\mathbf{C}$ to $\mathbf{~}$ \\
\hline g-C $\mathbf{C}_{\mathbf{3}} \mathbf{N}_{\mathbf{4}}$ powder & 34.53 & 1.53 & 60.93 & - & 0.6611 \\
\hline $\mathbf{C u}-\mathbf{g}-\mathbf{C}_{\mathbf{3}} \mathbf{N}_{\mathbf{4}} \mathbf{p o w d e r}$ & 32.19 & 1.14 & 56.47 & 6.98 & 0.6665 \\
\hline $\mathbf{g}-\mathbf{C}_{\mathbf{3}} \mathbf{N}_{\mathbf{4}}$ film & 33.11 & 1.80 & 57.95 & - & 0.6650 \\
\hline $\mathbf{C u} \mathbf{- g}-\mathbf{C}_{\mathbf{3}} \mathbf{N}_{\mathbf{4}}$ film & 33.67 & 1.38 & 52.85 & 11.38 & 0.7432 \\
\hline
\end{tabular}

Elemental analysis results support the formation of C-C defects as seen in XPS (Figure S10). The atomic ratio of $\mathrm{C}$ to $\mathrm{N}$ of undoped $\mathrm{g}-\mathrm{C}_{3} \mathrm{~N}_{4}$ has been reported to around 0.68 which is the value that is obtained for the samples in this work, except for $\mathrm{Cu}-\mathrm{g}-\mathrm{C}_{3} \mathrm{~N}_{4}$ film where the ratio is much higher. ${ }^{15}$ This ratio is lower than the ideal stoichiometric ratio of 0.75 , likely due to N-termination as observed in XPS (Figure $\mathrm{S} 10$ ). The increase in $\mathrm{C}$ to $\mathrm{N}$ ratio from the powder to film for the $\mathrm{Cu}$-doped analogue further supports the formation of $\mathrm{C}-\mathrm{C}$ defect sites. One further notable result in the elemental analysis is the change in mass percentage of $\mathrm{Cu}$ relative to $\mathrm{C}, \mathrm{N}$, and $\mathrm{H}$ due to the film preparation procedure. The mass percentage of $\mathrm{Cu}$ increases approximately $62 \%$ from powder to film which is explained by the removal of $\mathrm{C}$ and $\mathrm{N}$ from the sample during the annealing process. The annealing is performed at 470 degrees Celsius whereas the synthesis of $\mathrm{g}-\mathrm{C}_{3} \mathrm{~N}_{4}$ is performed at 550 degrees Celsius; however, several reagents are present in the film paste precursor that contribute to the loss of $\mathrm{C}$ and $\mathrm{N}$ in the $\mathrm{Cu}-\mathrm{g}-\mathrm{C}_{3} \mathrm{~N}_{4}$ film (see Experimental). The increase in $\mathrm{C}$ to $\mathrm{N}$ ratio close to the ideal value of 0.75 was also observed.

\section{Atomic Cartesian Coordinates for EXAFS Models}

Model A (20 Atoms)

$\begin{array}{lccc}\text { Atom } & \mathrm{X} & \mathrm{Y} & \mathrm{Z} \\ \mathrm{C} & 3.18024 & 11.39935 & 7.56650 \\ \mathrm{C} & 3.71811 & 12.53747 & 3.90736 \\ \mathrm{C} & 4.38924 & 9.39635 & 7.15950 \\ \mathrm{C} & 5.93711 & 8.55447 & 3.49936 \\ \mathrm{C} & 3.17824 & 7.51435 & 6.97250 \\ \mathrm{C} & 5.42024 & 11.38235 & 7.34550 \\ \mathrm{C} & 7.14811 & 10.43647 & 3.31336 \\ \mathrm{C} & 0.97824 & 11.37335 & 7.15950 \\ \mathrm{C} & 5.92011 & 12.56347 & 3.49936 \\ \mathrm{~N} & 4.32224 & 12.05535 & 7.69850 \\ \mathrm{~N} & 2.57711 & 11.88047 & 4.03936 \\ \mathrm{~N} & 7.17111 & 11.83847 & 3.49936\end{array}$




$\begin{array}{llll}\mathrm{N} & 3.20024 & 10.08535 & 7.15950 \\ \mathrm{~N} & 1.99124 & 11.94535 & 7.78850 \\ \mathrm{~N} & 4.90811 & 11.99147 & 4.12836 \\ \mathrm{~N} & 4.35624 & 8.08835 & 7.07850 \\ \mathrm{~N} & 5.50824 & 10.07435 & 7.24050 \\ \mathrm{~N} & 5.97011 & 9.86247 & 3.41836 \\ \mathrm{~N} & 4.81811 & 7.87647 & 3.58036 \\ \mathrm{Cu} & 4.40664 & 10.17721 & 4.48360\end{array}$

Model B (19 Atoms)

\begin{tabular}{|c|c|c|c|}
\hline Atom & $X$ & $\mathrm{Y}$ & Z \\
\hline $\mathrm{C}$ & 2.05024 & 9.44935 & 6.75250 \\
\hline $\mathrm{C}$ & 3.18024 & 11.39935 & 7.56650 \\
\hline $\mathrm{C}$ & 3.71811 & 12.53747 & 3.90736 \\
\hline $\mathrm{C}$ & 4.38924 & 9.39635 & 7.15950 \\
\hline $\mathrm{C}$ & 5.42024 & 11.38235 & 7.34550 \\
\hline $\mathrm{C}$ & 0.25011 & 10.43647 & 3.31336 \\
\hline $\mathrm{C}$ & 1.47811 & 12.55447 & 3.68636 \\
\hline $\mathrm{C}$ & 7.14811 & 10.43647 & 3.31336 \\
\hline $\mathrm{C}$ & 5.92011 & 12.56347 & 3.49936 \\
\hline $\mathrm{N}$ & 4.32224 & 12.05535 & 7.69850 \\
\hline $\mathrm{N}$ & 1.38011 & 9.81747 & 2.96036 \\
\hline $\mathrm{N}$ & 2.57711 & 11.88047 & 4.03936 \\
\hline $\mathrm{N}$ & 0.27311 & 11.83847 & 3.49936 \\
\hline $\mathrm{N}$ & 7.17111 & 11.83847 & 3.49936 \\
\hline $\mathrm{N}$ & 3.20024 & 10.08535 & 7.15950 \\
\hline $\mathrm{N}$ & 4.90811 & 11.99147 & 4.12836 \\
\hline $\mathrm{N}$ & 5.50824 & 10.07435 & 7.24050 \\
\hline $\mathrm{N}$ & 5.97011 & 9.86247 & 3.41836 \\
\hline $\mathrm{Cu}$ & 3.79009 & 10.52348 & 4.63325 \\
\hline
\end{tabular}




\section{References}

(1) Chung, Y. J.; Lee, B. I.; Ko, J. W.; Park, C. B. Photoactive g- $\mathrm{C}_{3} \mathrm{~N}_{4}$ Nanosheets for Light-Induced Suppression of Alzheimer's $\beta$-Amyloid Aggregation and Toxicity. Adv. Healthc. Mater. 2016, 5, 1560-1565. DOI: 10.1002/adhm.201500964.

(2) Ito, S.; Chen, P.; Comte, P.; Nazeeruddin, M. K.; Liska, P.; Péchy, P.; Grätzel, M. Fabrication of Screen-printing Pastes from $\mathrm{TiO}_{2}$ Powders for Dye-sensitised Solar Cells. Prog. Photovolt. 2007, 15, 603-612. DOI: 10.1002/pip.768.

(3) Barron, V.; Torrent, J. Use of the Kubelka-Munk theory to study the influence of iron oxides on soil colour. Journal of Soil Science 1986, 37, 499-510.

(4) Ravel, B.; Newville, M. Athena, Artemis, Hephaestus: Data Analysis for X-ray Absorption Spectroscopy using IFEFFIT. J. Synchrotron Rad. 2005, 12, 537-541. DOI: 10.1107/S0909049505012719.

(5) Regan, K. P.; Swierk, J. R.; Neu, J.; Schmuttenmaer, C. A. Frequency-Dependent Terahertz Transient Photoconductivity of Mesoporous $\mathrm{SnO}_{2}$ Films. J. Phys. Chem. C 2017, 121, 1594915956. DOI: 10.1021/acs.jpcc.7b02318.

(6) Smith, N. V. Classical generalization of the Drude formula for the optical conductivity. Phys. Rev. B 2001, 64, 155106. DOI: 10.1103/PhysRevB.64.155106.

(7) Cocker, T. L.; Baillie, D.; Buruma, M.; Titova, L. V.; Sydora, R. D.; Marsiglio, F.; Hegmann, F. A. Microscopic origin of the Drude-Smith model. Phys. Rev. B 2017, 96, 205439. DOI: 10.1103/PhysRevB.96.205439.

(8) Neu, J.; Schmuttenmaer, C. A. Tutorial: An introduction to terahertz time domain spectroscopy (THz-TDS). J. Appl. Phys. 2018, 124, 231101. DOI: 10.1063/1.5047659.

(9) Pattengale, B.; Neu, J.; Ostresh, S.; Hu, G.; Spies, J. A.; Okabe, R.; Brudvig, G. W.; Schmuttenmaer, C. A. Metal-Organic Framework Photoconductivity via Time-Resolved Terahertz Spectroscopy. J. Am. Chem. Soc. 2019, 141, 9793-9797. DOI: 10.1021/jacs.9b04338.

(10) Neu, J.; Regan, K. P.; Swierk, J. R.; Schmuttenmaer, C. A. Applicability of the thin-film approximation in terahertz photoconductivity measurements. Appl. Phys. Lett. 2018, 113, 233901. DOI: 10.1063/1.5052232.

(11) Thomas, A.; Fischer, A.; Goettmann, F.; Antonietti, M.; Müller, J.-O.; Schlögl, R.; Carlsson, J. M. Graphitic carbon nitride materials: variation of structure and morphology and their use as metalfree catalysts. J. Mater. Chem. 2008, 18, 4893-4908. DOI: 10.1039/B800274F.

(12) Zhang, G.; Zhang, J.; Zhang, M.; Wang, X. Polycondensation of thiourea into carbon nitride semiconductors as visible light photocatalysts. J. Mater. Chem. 2012, 22, 8083-8091. DOI: 10.1039/C2JM00097K

(13) Yue, B.; Li, Q.; Iwai, H.; Kako, T.; Ye, J. Hydrogen production using zinc-doped carbon nitride catalyst irradiated with visible light. Sci. Technol. Adv. Mater. 2011, 12, 034401. DOI: 10.1088/1468-6996/12/3/034401.

(14) Thaweesak, S.; Wang, S.; Lyu, M.; Xiao, M.; Peerakiatkhajohn, P.; Wang, L. Boron-doped Graphitic Carbon Nitride Nanosheets for Enhanced Visible Light Photocatalytic Water Splitting. Dalton Trans. 2017, 46, 10714-10720. DOI: 10.1039/C7DT00933J.

(15) Fina, F.; Callear, S. K.; Carins, G. M.; Irvine, J. T. S. Structural Investigation of Graphitic Carbon Nitride via XRD and Neutron Diffraction. Chem. Mater. 2015, 27, 2612-2618. DOI: 10.1021/acs.chemmater.5b00411. 